\title{
Battery Resistance Compensation in Access System
}

\author{
Songyang Ma, Haiying Wang, Yubing Dong and Fazhong Jian \\ School of Automation, Harbin University of Science and Technology \\ No. 52 Xuefu Road, Nangang District, Harbin, China \\ Corresponding Author: why.69@163.com
}

\begin{abstract}
At present, the study of the battery internal resistance at home and abroad is also a weak link, the inaccuracy of internal resistance measurement has become the biggest problem of current battery detection, which directly affects the battery capacity to play effectively, reducing the safety and reliability using of battery, making the battery charge and discharge control lack of sufficient reference. In this paper, a large number of experiment data were analyzed and sorted out, and various factors affecting the internal resistance were summed up. Conduct predictive parsing based on the summary factors and SPSS software and the multiple linear regression prediction method based on the statistical prediction was proposed to compensate resistance in access system, and take the algorithm compensation to error of the internal resistance measurement which affected by many factors. After the system applied compensation, the smallest resolution of measured resistance is $0.003 \mathrm{~m} \Omega$. The measurement accuracy may reach to $1 \%$ under complex site conditions. The equipment meets the requirements that projects propose and realizes accurate real-time measurement of multiple battery resistance.
\end{abstract}

Keywords: Internal resistance compensation; Multiple linear regression prediction; SPSS; Access system

\section{Introduction}

With the application of access system more and more widespread, more and more attention has been paid to the detection of battery internal resistance in access system. As an important technical index to measure the battery performance, how to improve the accuracy of the measured value has become one of the important research topics. At present, most of the internal resistance test circuit for the precision components and highprecision chip, the power supply system will be charged when the charger charging ripple current under long-time working, strong current conditions and the magnetic field generated by long-term work equipment temperature and many other factors interfere with, resulting in the value of the temporary measurement of internal resistance inaccurate. Although the access system has used a lot of hardware filtering compensation methods, but because the above factors are strong interference, it is difficult to shield off in real life, it will lead to the measured value of the internal resistance in access system resulting in an error, so that the value of inaccurate [1].

In this paper, we predict the strategy of the close value of battery resistance in access system by analyzing collected parameters such as battery terminal voltage, current flowing through the battery and the ambient temperature and combining multiple linear regression algorithm. It compensates the measurement error caused by many non-human factors, improves the measurement accuracy of resistance and provides basis for the battery life prediction and the battery failure evaluation 


\section{Factors Affecting the Inaccuracy of Measurement of Internal Resistance and its Solution}

In order to solve the problem of inaccurate measurement caused by the ripple current and aging of the reference resistance in access system during charging, it is necessary to compensate the measurement misalignment.

Otherwise it will cause unnecessary economic loss and waste of resources. In the compensation, the hardware compensation filter cannot play a very good role, and the hardware measurement part of the internal resistance in access system of the measurement circuit and the floating state of the battery voltage, current and temperature parameters of the acquisition circuit is completely independent of the distinction. Some parameters such as voltage, current and temperature in the floating state have some influences on the change of resistance in a certain meaning. Thus, in this paper we use the multiple linear regression algorithm. Model the multiple regression prediction to the resistance through the above three parameters and transplant the model to software program of resistance measurement system, which can make the access system judge whether the situation that the measurement is inaccurate instead of the resistance getting bigger in a certain triggering condition. This way we compensate the accuracy of the method of software algorithm.

\section{Analysis of Multiple Linear Regression Internal Resistance Compensation Method}

\subsection{Multiple Linear Regression Internal Resistance Compensation Method}

There is no deterministic functional relationship between dependent and independent variables, but there is some correlation, and there are also many unpredictable random factors that affect the connection between them, then we can establish a regression model to study this type of problem.

After establishing the regression model, the estimated value $a_{1}, \cdots, a_{k}$ of the obtained regression coefficient is $\beta_{1}, \cdots, \beta_{k}$ according to the least squares method, and the sum of squared errors is obtained [6].

When $\left(\beta_{1}, \cdots, \beta_{k}\right)=\left(a_{1}, \cdots, a_{k}\right)$ reaches a minimum, $a_{1}, \cdots, a_{k}$ called regression coefficient $\beta_{1}, \cdots, \beta_{k}$ 's point estimates. After finding the point estimate $a_{1}, \cdots, a_{k}$ of the regression coefficients, namely $\delta_{i}=y_{i}-f\left(x_{i} ; a_{1}, \cdots, a_{k}\right)$, called residuals; $\sum_{i=1}^{n} \delta^{2}$ called the residual sum of squares, abbreviated as $R S S$; mark as $s^{2}=R S S$ / $(n-k)$, called the residual variance, and $s$ called residual standard deviation, $s^{2}$ is $\delta^{2}$ point estimates.

For the independent variable $\mathrm{X}$ have any value $x=x_{0}$ in the domain, mark as $\widehat{\mu}_{0}=f\left(x_{0} ; a_{1}, \cdots, a_{k}\right)$, called $\widehat{\mu}_{0}$ is point estimation when Independent variable $x=x_{0}$ correspond the average value $\mu_{0}=f\left(x_{0} ; a_{1}, \cdots, a_{k}\right)$, also called $\widehat{\mu}_{0}$ point prediction when Independent variable $x=x_{0}$ have observations $y_{0}=\mu_{0}+\varepsilon_{0}$.

\subsection{Establishment of Mathematical Model for Multiple Linear Regression Analysis}

The multiple linear regression model in this system is established and validated by SPSS data analysis software. By battery internal resistance meter site monitoring data, continuous real-time measurement of battery float voltage single health state, current, temperature and internal resistance, through collection the date for 60 hours, we can find 
the data samples. Import the data to SPSS software, take the regression analysis performed about $\mathrm{X}=$ Voltage, $\mathrm{Y}=$ Current, $\mathrm{Z}=$ temperature and $\mathrm{U}=$ Internal resistance.

Table 3-1 shows the basic description of the variables.

Table 3-1. Statistics of Variables

\begin{tabular}{c|c|c|c|c|c}
\hline & $\mathrm{N}$ & $\begin{array}{c}\text { Minimum } \\
\text { value }\end{array}$ & Maximum & Mean & $\begin{array}{c}\text { Standard } \\
\text { deviation }\end{array}$ \\
\hline $\mathrm{x}=$ Voltage/V & 50 & 13.32 & 14.10 & 14.0007 & 0.24192 \\
\hline $\mathrm{y}=$ Current/A & 50 & 0.4800 & 4.8900 & 1.562667 & 1.3218246 \\
\hline $\mathrm{z}=$ Temperature $/{ }^{\circ} \mathrm{C}$ & 50 & 22 & 25 & 23.90 & 1.094 \\
\hline $\mathrm{u}=$ Internal resistance $/ \mathrm{m} \Omega$ & 50 & 33.8000 & 44.3000 & 36.243333 & 3.2109386 \\
\hline Effective N & 50 & N/A & N/A & N/A & N/A \\
\hline
\end{tabular}

A statistical table shows, there are no missing data, Missing value processing is not required. The resulting correlations are detected as shown in the Table 3-2.

Table 3-2. Table of Correlation Detection

\begin{tabular}{|c|c|c|c|c|c|}
\hline \multicolumn{6}{|c|}{ Correlation } \\
\hline & & $\mathrm{x}=$ Voltage $/ \mathrm{V}$ & $\mathrm{y}=$ Current $/ \mathrm{A}$ & $\begin{array}{c}\mathrm{z}=\text { Temperatur } \\
\mathrm{e} /{ }^{\circ} \mathrm{C}\end{array}$ & $\begin{array}{c}\mathrm{u}=\text { Internalresis } \\
\tan \mathrm{t} / \mathrm{m} \Omega\end{array}$ \\
\hline \multirow[t]{3}{*}{$\mathrm{x}=$ Voltage $/ \mathrm{V}$} & $\begin{array}{c}\text { Pearson } \\
\text { Correlation }\end{array}$ & 1 & $0.808 * *$ & 0.316 & $0.769 * *$ \\
\hline & $\begin{array}{c}\text { Significance } \\
\text { (Bilateral) }\end{array}$ & & 0.000 & 0.089 & 0.000 \\
\hline & $\mathrm{N}$ & 50 & 50 & 50 & 50 \\
\hline \multirow[t]{3}{*}{$\mathrm{y}=$ Current $/ \mathrm{A}$} & $\begin{array}{c}\text { Pearson } \\
\text { Correlation }\end{array}$ & $0.808 * *$ & 1 & 0.016 & $0.985 * *$ \\
\hline & $\begin{array}{c}\text { Significance } \\
\text { (Bilateral) }\end{array}$ & 0.000 & & 0.933 & 0.000 \\
\hline & $\mathrm{N}$ & 50 & 50 & 50 & 50 \\
\hline \multirow[t]{3}{*}{$\begin{array}{c}\mathrm{z}=\text { Temperatu } \\
\mathrm{re} /{ }^{\circ} \mathrm{C}\end{array}$} & $\begin{array}{c}\text { Pearson } \\
\text { Correlation }\end{array}$ & 0.316 & 0.016 & 1 & $0.877 * *$ \\
\hline & $\begin{array}{c}\text { Significance } \\
\text { (Bilateral) }\end{array}$ & 0.089 & 0.933 & & 0.970 \\
\hline & $\mathrm{N}$ & 50 & 50 & 50 & 50 \\
\hline \multirow[t]{3}{*}{$\begin{array}{c}\mathrm{u}=\text { Internalres } \\
\text { istant } / \mathrm{m} \Omega\end{array}$} & $\begin{array}{c}\text { Pearson } \\
\text { Correlation } \\
\end{array}$ & $0.769 * *$ & $0.985 * *$ & $0.877 * *$ & 1 \\
\hline & $\begin{array}{c}\text { Significance } \\
\text { (Bilateral) }\end{array}$ & 0.000 & 0.000 & 0.970 & \multirow[b]{2}{*}{$-50^{-}$} \\
\hline & $\mathrm{N}$ & 50 & 50 & 50 & \\
\hline
\end{tabular}

From the correlation test, voltage, current, temperature and resistance were significantly correlated with the level of 0.01 , so you can establish the regression equation.

The coefficients of multiple regression model are shown as Table 3-3. 
Table 3-3. Coefficient of Multiple Linear Regression Model

\begin{tabular}{|c|c|c|c|c|c|c|c|c|}
\hline & \multirow[t]{2}{*}{ model } & \multicolumn{2}{|c|}{$\begin{array}{l}\text { Non-standard } \\
\text { coefficient }\end{array}$} & \multirow{2}{*}{\begin{tabular}{|c|}
$\begin{array}{c}\text { Standardized } \\
\text { coefficients }\end{array}$ \\
trial version
\end{tabular}} & \multirow[t]{2}{*}{$\mathrm{t}$} & \multirow[t]{2}{*}{ Sig. } & \multicolumn{2}{|c|}{ Collinearity statistics } \\
\hline & & B & $\begin{array}{c}\text { Standard } \\
\text { error }\end{array}$ & & & & Tolerance & VIF \\
\hline \multirow{4}{*}{1} & (Constant) & 12.350 & 11.118 & & 1.111 & 0.047 & & \\
\hline & $\begin{array}{c}\mathrm{x}=\text { Voltage } \\
/ \mathrm{V}\end{array}$ & 1.661 & 0.871 & 0.125 & 1.906 & 0.038 & 0.239 & 4.184 \\
\hline & 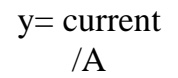 & 2.639 & 0.151 & 1.086 & 17.442 & 0.000 & 0.265 & 3.768 \\
\hline & $\begin{array}{c}\mathrm{z}= \\
\text { temperature } \\
/{ }^{\circ} \mathrm{C}\end{array}$ & -0.146 & 0.114 & -0.050 & -1.284 & 0.011 & 0.689 & 1.452 \\
\hline
\end{tabular}

a. The dependent variable: $\mathrm{u}=$ Resistance $/ \mathrm{m} \Omega$

Therefore, the regression model for measuring the internal resistance of the battery:

$$
u=1.661 x+2.639 y-0.146 z+12.350
$$

Among them, $\mathrm{u}$ represents the predicted internal resistance, $\mathrm{x}, \mathrm{y}, \mathrm{z}$ represent the measured value of the system battery voltage, current and temperature values. The above table we can know, Sig values of the four factors $(0.047,0.038,0.000,0.011)$ were less than 0.05 , indicating that the prediction results are valid within 0.05 , $t$-test that is significant. Variance Inflation Factor VIF $<5$ description, there is no multicollinearity between the independent variables, we can create regression models.

\subsection{Verification of Multiple Regression Model}

The regression model was established by "regression" operation in the menu bar of SPSS software shown as the Table 3-4.

Table 3-4. Regression Model Summary

\begin{tabular}{c|c|c|c|c}
\hline model & $\mathrm{R}$ & $\mathrm{R}^{2}$ & ${\text { adjustment } \mathrm{R}^{2}}^{\text {Standard estimation }}$ \\
error
\end{tabular}

a. Predictors: (constant), $\mathrm{z}=$ temperature, $\mathrm{y}=$ current, $\mathrm{x}=$ voltage.

We can know from the Table $3-4, \mathrm{R}^{2}=0.973$ and adjusted $\mathrm{R}^{2}=0.970$. Their values are close to 1, the better regression model is, while the standard estimate of the error you need to be as small as possible, it can be seen, the regression model of this system is good.

From the software we can elicit Anova analysis of variance shown as the Table 3-5. 
Table 3-5. Anova Analysis of Variance

\begin{tabular}{l|c|c|c|c|c|c}
\hline \multicolumn{2}{c|}{ model } & Quadratic sum & df & $\begin{array}{c}\text { Mean } \\
\text { square }\end{array}$ & F & Sig. \\
\hline 1 & regression & 290.988 & 3 & 96.996 & 315.034 & 0.000 \\
\hline & $\begin{array}{c}\text { Residual } \\
\text { error }\end{array}$ & 8.005 & 26 & 0.308 & & \\
\hline & \begin{tabular}{c} 
aggregate \\
\hline
\end{tabular}
\end{tabular}

a. dependent variable: $\mathrm{u}=$ internal resistance

\section{b. Predictors: (constant), $\mathrm{z}=$ temperature, $\mathrm{y}=$ current, $\mathrm{x}=$ voltage}

From the Table 3-5, F inspection the value of Sig is $0.000<0.05$, which explains that the whole regression model has a significant effect and the significance of the equation is good. Residual graph of regression model diagnosis is shown as 3-1.

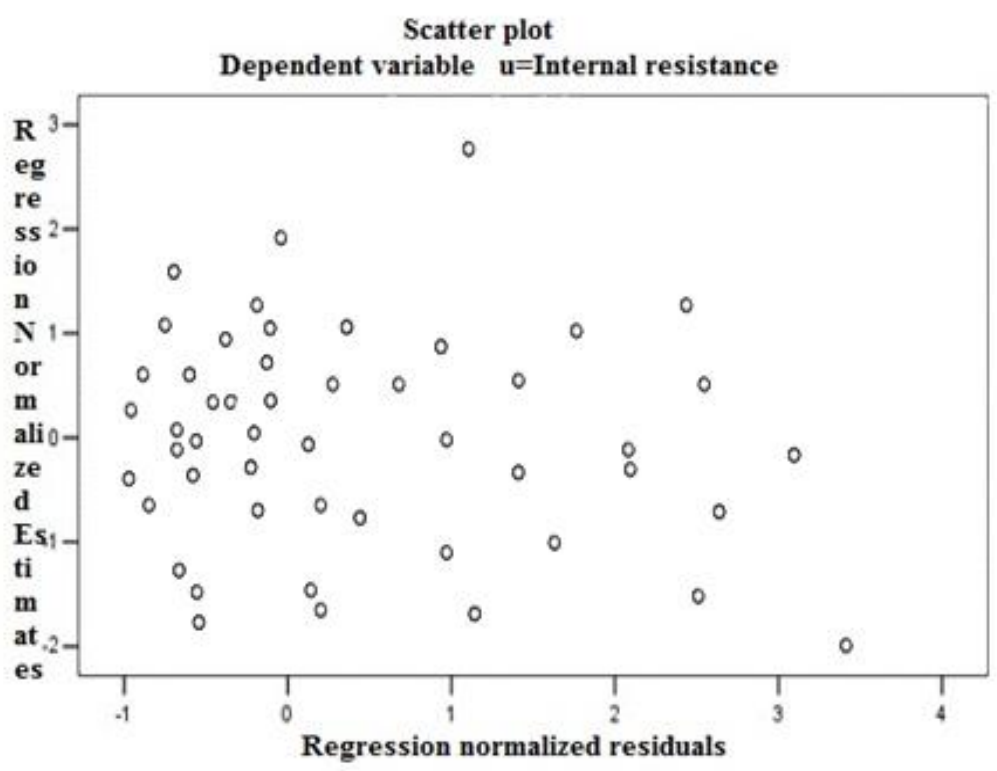

Figure 3-1. Residual Graph of Regression Model Diagnosis

The residual figure shows that the point is not in the graph is a trend and a more uniform distribution in the straight line on both sides, so the residual variance with normality and etc., so prediction model of significant is good.

\subsection{Combined with the Compensation Method of Experimental Results Analysis}

10 sets of data collected from the field devices in access system were randomly selected and the collected values of voltage, current and temperature were taken into the prediction model to obtain the predicted values. Measured internal resistance and internal resistance comparison table shown in the Table 3-6. 
Table 3-6. Data Collected at Random and the Predicted Value

\begin{tabular}{|c|c|c|c|c|}
\hline $\mathrm{x}=$ Voltage $/ \mathrm{V}$ & $\mathrm{y}=$ Current $/ \mathrm{A}$ & $\mathrm{z}=$ Temperature $/{ }^{\circ} \mathrm{C}$ & $\begin{array}{c}\mathrm{u}=\text { Internal } \\
\text { resistance } / \mathrm{m} \Omega\end{array}$ & $\begin{array}{c}\mathrm{uf}=\text { Predictive } \\
\text { internal } \\
\text { resistance } / \mathrm{m} \Omega\end{array}$ \\
\hline 14.1 & 1.08 & 25 & 34.8 & 34.97022 \\
\hline 14.09 & 1.38 & 25 & 35.8 & 35.74531 \\
\hline 14.1 & 0.72 & 22 & 34.3 & 34.45818 \\
\hline 14.1 & 0.68 & 22 & 34.3 & 34.35262 \\
\hline 14.1 & 0.67 & 22 & 34.2 & 34.32623 \\
\hline 14.09 & 1.73 & 25 & 36 & 36.36896 \\
\hline 14.1 & 1.65 & 25 & 35.8 & 36.47445 \\
\hline 13.32 & 4.01 & 23 & 41.7 & 41.69891 \\
\hline 13.49 & 4.01 & 23 & 41.9 & 41.98128 \\
\hline 14.07 & 3.81 & 25 & 41.9 & 42.12486 \\
\hline
\end{tabular}

By contrast, the difference between the predicted value and the measured value is not more than 0.5 , the prediction accuracy is about $1.19 \%$. Therefore, the prediction model has good prediction and practical reference value. Use Matlab software to draw the contrast curve between the predicted value and the real value intuitively as shown in Figure 3-2.

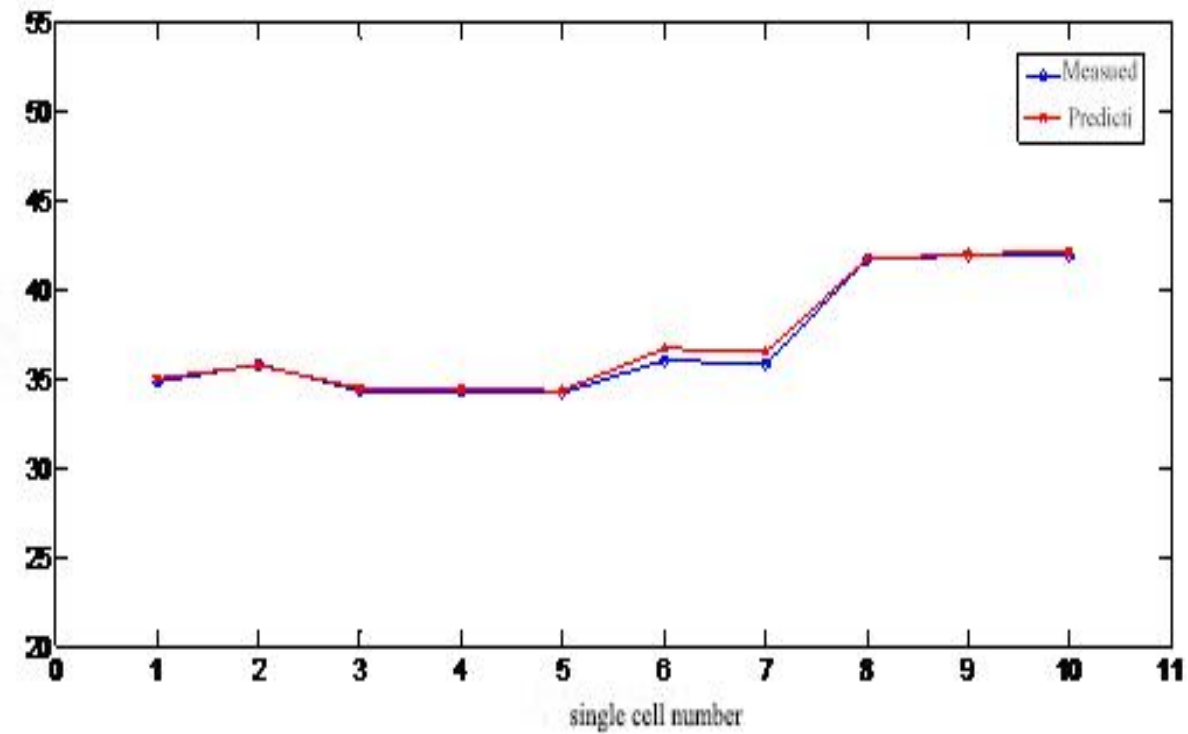

Figure 3-2. Comparison Curve of Predictive Value and Actual Value

\section{Conclusion}

The premise of ensuring that the access system can be normal operation is to make sure the batteries can operate safely and effectively. It has an important meaning to detect the batteries operation state of the power in access system accurately in the real life. However, the battery detection system is still a weakness at home and abroad. In domestic battery detection system is still at the start-up phase. Most systems use the hardware filtering methods to improve the accuracy. However, due to the factors of influencing the resistance value are all strong interferences so that it is hard to shield off the factors in reality only by the hardware filtering compensating method. It may lead to the 
misalignment phenomenon of the resistance measurement value and may make the operators operate wrongly because of the inaccurate measurements and resulting in unnecessary losses.

In this paper, we analyze that it is hard to improve the accuracy by hardware filtering compensation and the factors which may lead to the measurements inaccurate. Then we put forward the theory of multiple linear regression compensation. Set up the mathematical model by analyzing the collecting data and combining SSPS statistical analysis software. In the end, put forward the algorithm compensation of multiple linear regression predicting analyzing based on statistical prediction. This system compensates the error in resistance measurement after using the algorithm compensation. The system meets the project requirements, improves the measurement accuracy and realizes the online precise measurement to multi- cell resistance in access system.

\section{References}

[1] J. Xu, "Based on the multiple regression prediction lossless hyperspectral image compression", Xi 'an university of electronic science and technology, (2014), pp. 31-35.

[2] H. Tang, "Multiple regression and neural network application in the Wuhan city real estate forecast more", Huazhong university of science and technology, (2013), pp. 39-41.

[3] B. Siva Soumya, M. Sekhar, J. Riotte and J.-J. Braun, "Non-linear regression model for spatial variation in precipitation chemistry for South India", Atmospheric Environment, vol. 65, no. 43, (2009), pp. 11471152.

[4] N. Li, "Multivariate nonlinear regression analysis in the application of fabric dyeing computer color matching research", Qingdao University, (2014), pp. 20-28.

[5] B. Pattipati, "System identification and estimation framework for pivotal automotive battery management system characteristics", Systems, Man, and Cybernetics, Part C: Applications and Reviews, IEEE Transactions, vol. 41, no. 6, (2011), pp. 869-884.

[6] K. W. E. Cheng, "Battery-management system (BMS) and SOC development for electrical vehicles", Vehicular Technology, IEEE Transactions, vol. 60, no. 1, (2011), pp. 76-88.

[7] V. Mark and T. Edward, "Adaptive state of charge for nickel metal hydride batteries including hysteresis phenomena", Power Sources, vol. 26, no. 41, (2011), pp. 236-249.

[8] L. W. Juang, "System identification-based lead-acid battery online monitoring system for electric vehicles", Energy Conversion Congress and Exposition (ECCE), 2010 IEEE, vol. 32, no. 6, (2010), pp. 3903-3910.

[9] W. Liu, "A new type of internal resistance tester development”, Journal of Guangdong education, vol. 1, (2011), pp. 57-58.

[10] Z. Yang, "Battery internal resistance measurement system design", Aerospace measuring technology, vol. 1, (2011), pp. 53-5. 
International Journal of Energy, Information and Communications Vol.8, Issue 2 (2017) 